\title{
Reversible acute Fontan circulation failure secondary to retrogradely conducted junctional rhythm: clinical echocardiographic correlation
}

Paolo Ferrero ${ }^{1,2^{*}}$ D, Isabelle Piazza ${ }^{2,3}$, Youcef Sadou ${ }^{4}$ and Matteo Ciuffreda ${ }^{5}$

\begin{abstract}
Background: Sequential atrioventricular activation plays a critical role in the physiology of Fontan circulation. Although bradycardia is usually well tolerated, retrogradely conducted junctional rhythm may acutely increase atrial pressure impairing cardiac output. Echocardiographic evaluation can reveal clues of this hemodynamic condition. The clinical impact of arrhythmic disturbance on the follow up of patients who had undergone total cavopulmonary connection is well recognized but the role of, transient periods of retrogradely conducted junctional rhythm on the immediate post-operative course is less defined.

Case presentation: We describe two cases of acute Fontan circulatory failure due to postoperative retrogradely conducted junctional escape rhythm despite an adequate heart rate and circadian variation. The patients rapidly improved after atrial pacing, allowing discharge with a minimal dose of diuretic.

Conclusion: In the absence of any hemodynamic target, hearth rhythm should be systematically checked after TCPC irrespective of adequacy of heart rate. Likewise, efficiency of temporary atrial pacing should be granted and surgeons should have a low threshold for epicardial lead implantation.
\end{abstract}

Keywords: Heart failure, Pediatric echocardiography, Cardiac pacing, Congenital heart disease

\footnotetext{
* Correspondence: ferrerop41@gmail.com

${ }^{1}$ ACHD Unit - Pediatric and Adult Congenital Heart Centre, IRCCS Policlinico

San Donato, San Donato Milanese, Milan, Italy

University of Milan, Milan, Italy

Full list of author information is available at the end of the article
}

(c) The Author(s). 2021 Open Access This article is licensed under a Creative Commons Attribution 4.0 International License, which permits use, sharing, adaptation, distribution and reproduction in any medium or format, as long as you give appropriate credit to the original author(s) and the source, provide a link to the Creative Commons licence, and indicate if changes were made. The images or other third party material in this article are included in the article's Creative Commons licence, unless indicated otherwise in a credit line to the material. If material is not included in the article's Creative Commons licence and your intended use is not permitted by statutory regulation or exceeds the permitted use, you will need to obtain permission directly from the copyright holder. To view a copy of this licence, visit http://creativecommons.org/licenses/by/4.0/. The Creative Commons Public Domain Dedication waiver (http://creativecommons.org/publicdomain/zero/1.0/) applies to the data made available in this article, unless otherwise stated in a credit line to the data. 


\section{Background}

Fontan circulation critically depends on pulmonary resistance and atrial pressure [1]. It has been observed that during sinus rhythm blood predominantly flow during atrial relaxation. Furthermore the loss of atrioventricular synchrony may lead to phasic increase of atrial pressure which is transmitted to the Fontan circuit [2]. Heart rhythm optimization is recognized as a pivotal component of the follow up in this group of patients, while the impact of even self limited period of junctional rhythm is less defined, particularly wether the heart rate trend is acceptable.

We describe two cases of acute heart failure, after fenestrated total cavo-pulmonary connection (TCPC) which resolved after $48 \mathrm{~h}$ of atrial pacing. We demonstrated acute changes of Fontan flow pattern during the two modality of pacing that strictly correlated with the clinical status.

\section{Cases description}

The first patient was a 4 years old girl with hypoplastic left heart syndrome. She previously had undergone neonatal Norwood-Sano palliation and bidirectional cavopulmonary connection at the age of 3 months. Due to progressive cyanosis the patient was scheduled for tricuspid valve repair and TCPC. Preoperatively the patient had a well-tolerated junctional rhythm with constant retrograde conduction with preserved heart rate excursions.

Weaning from the bypass was uneventful and the patient was successfully extubated after $12 \mathrm{~h}$.

During the first postoperative week abdominal congestion, right pleural effusion (Fig. 1a) and progressive desaturation were observed. Blood chemistry disclosed increased liver enzymes and low albumin. Transthoracic echocardiogram showed normal ventricular function and mild AV valve regurgitation. Colour-Doppler interrogation of the
Fontan conduit and supra-hepatic veins, disclosed phasic hepatopetal signal consistent with a reversal flow through the fenestration on time with atrial retrograde conduction (Fig. 2). This observation was consistent with the evidence of giant 'atrial' wave one the jugular venous pressure tracing. Upon atrial pacing the reverse component of flow disappeared with a slight increase in aortic velocity time integral (VTI).

Clinically, these echocardiographic changes were accompanied by resolution of pleural effusion and progressive increase of oxygen saturation and albumin normalization during the following days (Fig. 1B). Based on this findings she was scheduled for permanent atrial pacing owing to persisting junctional rhythm.

The second patient was a 5 years old child who had undergone neonatal systemic to pulmonary shunt and cavo-pulmonary connection at the age of 9 months, due to severe symptomatic Ebstein anomaly. TCPC was planned because of progressive desaturation and effort intolerance. Few hours after cardiopulmonary bypass weaning he developed hypotension and low cardiac output syndrome requiring inotropic and vasopressor support. ECG disclosed competitive retrogradely conducted junctional rhythm. Function of the systemic ventricle and atrioventricular valve were normal. Similarly to the first case there was phasic reversal flow through the fenestration that was no longer detected during atrial pacing. Theses flow pattern changes translated into VTI increase and resolution of lactacidemia, in the following $24 \mathrm{~h}$, consistently with stroke volume and peripheral perfusion improvement. Permanent pacemaker implantation was not needed as sinus rhythm recovered after $72 \mathrm{~h}$.

\section{Discussion}

Despite surgical technical improvement, arrhythmic burden still represent a significant complication affecting

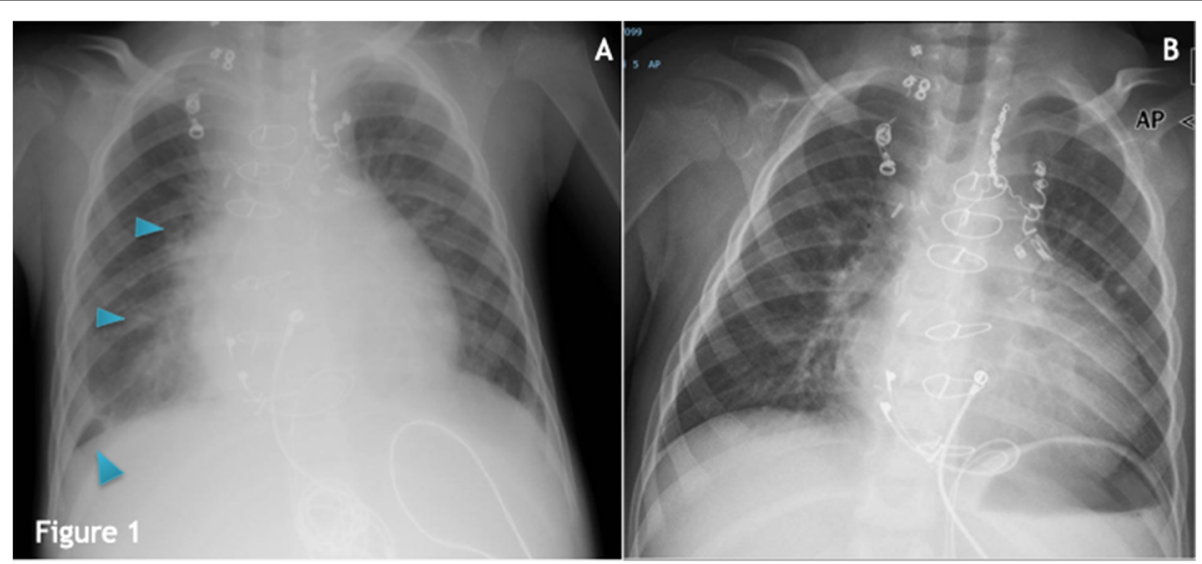

Fig. 1 Postoperative chest x-ray showing mild venous congestion and right pleural effusion (a) and normalization after $48 \mathrm{~h}$ atrial pacing (b) 


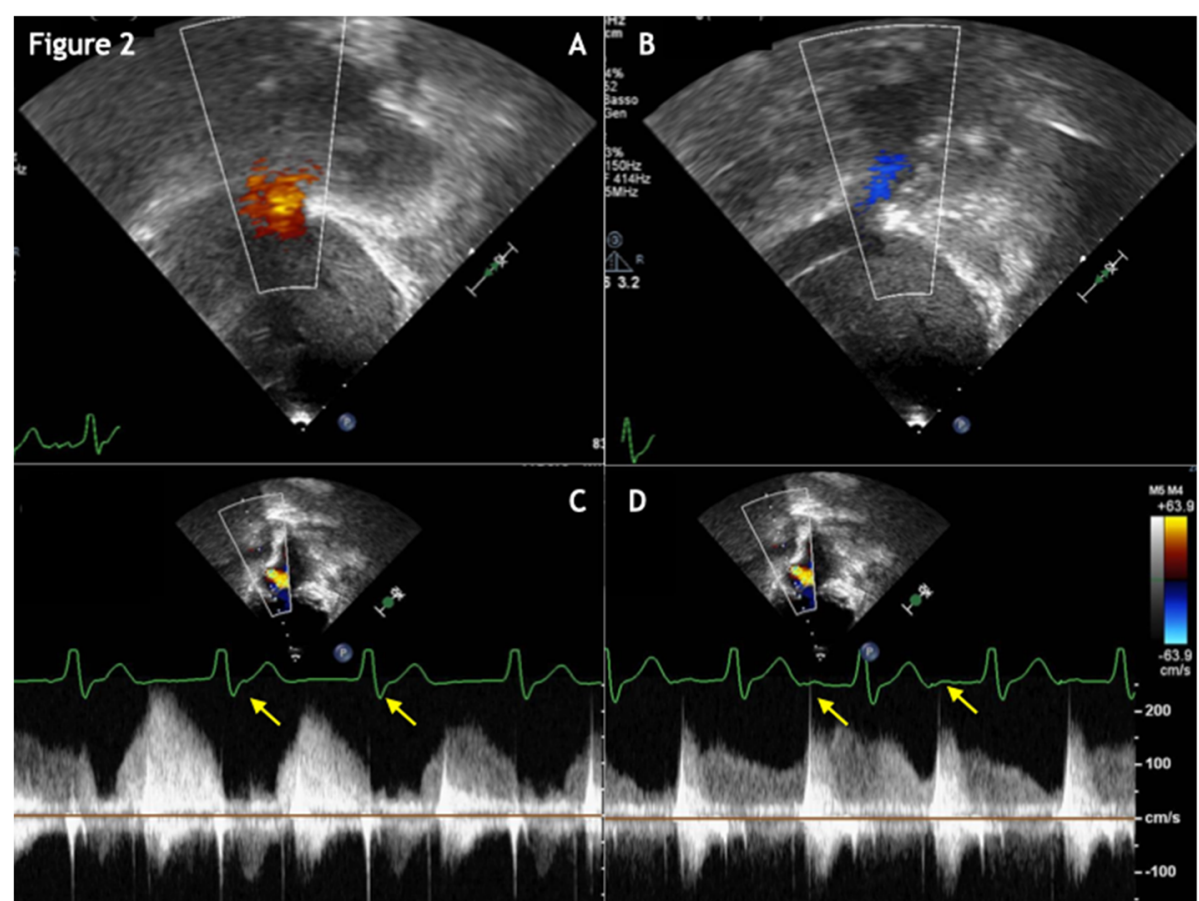

Fig. 2 Echocardiographic frame showing phasic inversion (a) and continuous (b) flow in the Fontan conduit during junctional rhythm and atrial paced rhythm, respectively (arrow). Pulse wave Doppler demonstrating inversion (c) and continuous (d) flow across the fenestration, during junctional and atrial paced rhythm, respectively. IVC: inferior vena cava

the follow up of Fontan patients [3, 4]. The effect of cavo-pulmonary anastomosis modification on the incidence of arrhythmias is controversial, in particular the extra cardiac total cavopulmonary connection does not obviate the occurrence of sinus node dysfunction $[4,5]$. The clinical impact of this condition is often underestimated as bradycardia is usually deemed to be well tolerated in the context of Fontan circulation, particularly in the presence of a junctional escape rhythm. Junctional rhythm in patients with Fontan circulation, by increasing the atrial pressure blunts the passive driving force of the Fontan circuit [2].

This cases provide the echocardiographic proof of the correlation between postoperative retrogradely conducted junctional escape rhythm and acute Fontan failure, which was completely reversible after atrial pacing.

It should be underscored that retrogradely conducted atrial activity, differently from dissociated junctional rhythm, by generating a rhythmic abnormal increase of atrial pressure, is one of the most important pathogenic determinants responsible for Fontan circulation failure in this clinical setting.

\section{Conclusion}

In the absence of any hemodynamic target, hearth rhythm should be systematically checked after TCPC irrespective of adequacy of heart rate. Likewise, efficiency of temporary atrial pacing should be granted and surgeons should have a low threshold for epicardial lead implantation.

\section{Acknowledgements}

None.

\section{Authors' contributions}

Dr. Ferrero contributed to research design, analysis and interpretation of data; he drafted the paper and approved the submitted and final versions. Dr. Piazza contributed to research acquisition and interpretation of data; she drafted the paper and approved the final version. Dr. Sadou contributed to research acquisition and analysis of data; he revised critically the paper and approved the final version. Dr. Ciuffreda contributed to research design and interpretation of data; he revised critically the paper and approved the final version.

\section{Authors' information}

Dr. Ferrero works as pediatric cardiologist in the ACHD unit at IRCCS Policlinico San Donato, in San Donato Milanese, Italy. Dr. Piazza is a Emergency medicine resident at University of Milan and works at Papa Giovanni XXIII Hospital in Bergamo - Italy. Dr. Sadou works as neonatologist in Neonatal intensive care unit at Papa Giovanni XXIII Hospital in Bergamo, Italy. Dr. Ciuffreda works as pediatric cardiologist at Papa Giovanni XXIII Hospital in Bergamo - Italy.

Funding

None.

Availability of data and materials Available. 


\section{Declarations}

\section{Ethics approval and consent to participate}

NA

\section{Consent for publication}

Verbally requested and obtained.

\section{Competing interests}

None.

\section{Author details}

${ }^{1}$ ACHD Unit - Pediatric and Adult Congenital Heart Centre, IRCCS Policlinico San Donato, San Donato Milanese, Milan, Italy. ${ }^{2}$ University of Milan, Milan, Italy. ${ }^{3}$ Emergency medicine department, ASST Papa Giovanni XXIII, Bergamo, Italy. ${ }^{4}$ Neonatal intensive care unit, ASST Papa Giovanni XXIII, Bergamo, Italy. ${ }^{5}$ Cardiolovascular department, ASST Papa Giovanni XXIII, Bergamo, Italy.

Received: 11 January 2021 Accepted: 7 April 2021

Published online: 15 April 2021

\section{References}

1. Rychik J, Fogel MA, Donofrio MT, et al. Comparison of patterns of pulmonary venous blood flow in the functional single ventricle heart after operative aortopulmonary shunt versus superior cavopulmonary shunt. Am J Cardiol. 1997:80:922-6.

2. Hasselman T, Schneider D, Madan N, Jacobs M. Reversal of fenestration flow during ventricular systole in Fontan patients in junctional or ventricular paced rhythm. Pediatr Cardiol. 2005;26:638-41.

3. Hakacova N, Lakomy M, Kovacikova L. Arrhythmias after Fontan operation: comparison of lateral tunnel and extracardiac conduit. J Electrocardiol. 2008; 41:173-7.

4. Stamm C, Friehs I, Mayer JE Jr, et al. Long-term results of the lateral tunnel Fontan operation. J Thorac Cardiovasc Surg. 2001;121:28-41.

5. Cohen Ml, Bridges ND, Gaynor JW, et al. Modifications to the cavopulmonary anastomosis do not eliminate early sinus node dysfunction. J Thorac Cardiovasc Surg. 2000;120:891-900.

\section{Publisher's Note}

Springer Nature remains neutral with regard to jurisdictional claims in published maps and institutional affiliations.

Ready to submit your research? Choose BMC and benefit from:

- fast, convenient online submission

- thorough peer review by experienced researchers in your field

- rapid publication on acceptance

- support for research data, including large and complex data types

- gold Open Access which fosters wider collaboration and increased citations

- maximum visibility for your research: over $100 \mathrm{M}$ website views per year

At BMC, research is always in progress.

Learn more biomedcentral.com/submissions 